\title{
Representações de Monstros, Figuras Humanas e Deuses na Grécia Antiga
}

Representations of monsters, human figures and gods in Ancient Greece

\author{
Ezio Pellizer*
}

J. L. Borges, "Epílogo", in Otras Inquisiciones, (1952):

“... estimar las ideas religiosas o filosóficas por su valor estético y aun por lo que encierran de singular y de maravilloso".

1. Morfologias Mudantes do Corpo Humano

No ano de 1928 (mil novecentos e vinte e oito), Fritz Saxl fez uma conferência (em alemão, mas que foi publicada mais tarde em inglês) com o título "Macrocosmo e microcosmo nas ilustrações medievais", em que ele examinou de um modo excelente um conceito fundamental nas operações do pensamento antigo - e talvez do pensamento humano em geral: a ideia (bastante estranha) de que exista uma secreta correspondência entre a estrutura do mundo e a figura humana; tudo o que fica no alto, de qualquer modo, o mais das vezes misterioso, acha uma correspondência com o que fica em baixo, e o cosmo se encontra em uma relação de analogia com o corpo humano. 
Os primeiros textos a atestar esta convicção seriam iranianos (do Irã), e falariam da criação do Primeiro Homem mais ou menos com estas palavras:

a cabeça dele é o mais alto dos céus, os olhos dele são o sol e a lua, os dentes são as estrelas, suas orelhas as janelas do céu, suas narinas a brisa do paraíso, à qual a boca dá acesso ${ }^{1}$.

Na idade helenística - diz Saxl, citando Reitzenstein e H. H. Schaeder $^{2}$ - esta concepção será estendida à astrologia, produzindo a concepção de um corpo humano correspondente ao zodíaco e, em seguida, a ideia de um "microcosmo", o homem, ao qual corresponderia um "macrocosmo" cuja força e energia estaria em uma relação de mútua correspondência com aquele.

A forma ideal do corpo humano (a anthròpou morphé) estaria também em relação com os ventos (a "rosa" dos ventos), com o ciclo astral (ou seja, o Zodíaco), e com os planetas, os quais, como todos sabem, são cinco, mais o sol e a lua ${ }^{3}$.

Uma engenhosa tentativa de vincular a estrutura simétrica do mundo com o primeiro ser humano (em formas que antecipam a Cabala medieval), encontra-se em alguns versos dos Oracula Sibyllina, onde, nas primeiras letras do nome de Adão, é reconhecida a presença dos quatro pontos cardeais, que por algum motivo oculto e misterioso são aqueles que se expressam em grego: Anatolé ou leste, Dýsis ou oeste, Árktos ou norte, Mesembríe ou sul (meio-dia).

Oracula Sibyll. 3, 24-26:

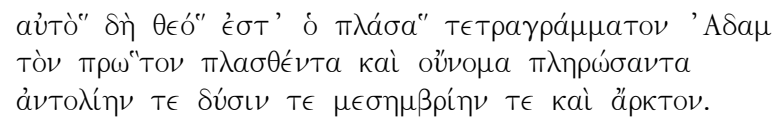

"e é o mesmo Deus, aquele que formou Adão com quatro letras 4 , o primeiro plasmado, cujo nome aponta [?]

o Leste, o Ocidente, o Meio dia, e a Ursa (constelação boreal)".

O Homem Cósmico Iraniano (apud SAxL,1957).

Cfr. Reitzenstein e H. H. Schaeder, 1926 (Synkretismus).

Nos manuscritos antigos, abundam as reproduções dessas imagens da rosa dos ventos ou do zodíaco em forma humana, cf. as figuras no já mencionado SAXL - SETTIS (1985).

Ou: "cujo nome tem quatro letras". 
Assim o corpo humano, com suas simetrias ou mesmo o nome do primeiro homem, podiam ser postos em relação com todo o cosmos. Na verdade, não parece que faltaram mesmo antes, já com alguns dos primeiros poetas da Grécia antiga, especialmente Hesíodo, tentativas mais frugais mas por vezes impressionantes para descrever grandezas cósmicas em forma humana, ou vice-versa. Nessas antigas concepções, ou melhor: nestas representações fantásticas do universo, podem-se ver várias tentativas, no modo analógico, fictício ou imaginário, para explorar a realidade empírica, descrevendo-a em um meio verbal ou icônico, com imagens que põem em jogo o princípio da analogia (e da polaridade, criando assim estruturas simétricas), estudado em um livro clássico de Geoffrey E. R. Lloyd ${ }^{5}$.

Esses enunciados, sejam verbais ou veiculados por outros sinais, constroem "mundos possíveis" nos quais aparecem descrições, morfologias geométricas (esferas, abóbadas celestes, cavidades, abismos, planos) ou taxonomias tiradas da natureza (os quatro elementos: ar, água, terra e fogo) isto é: descrições de estados da matéria ou de ações ou alterações (enunciados “performativos"), que tomam forma em uma primeira distinção, aliás fluída e mutável, entre quietude e movimento, entre animado e inanimado. Assim nasceu o conceito de alma (ou respiração, espírito) do mundo (anima mundi), uma ideia que pressupõe uma espécie de sopro ou respiração do universo, que reproduz de alguma forma algo de análogo à respiração humana (ou do mundo animado, a saber, dos animalia $)^{6}$. E é sempre o princípio gerativo por analogia aquele que produz concepções não uniformes - de diferentes épocas, mas de alguma maneira semelhantes e recorrentes - de uma correspondência entre o Macrocosmos (o mundo, o universo com seus planetas, o céu e as estrelas) e o Microcosmos, que é a figura do homem. Estas concepções, estas explorações gerativas de mundos possíveis (que se estendem em uma "longue durée") parecem tão enraizadas nos milênios, e tão inevitáveis, que fazem conjecturar que pertencem a estruturas morfogênicas profundas, de natureza psicológica, constitutivas do imaginário humano, como a luz e as trevas, o dia e a noite, o preto e o branco.

A tentativa de evocar algumas de suas linhas gerais nos leva a atravessar cosmogonias, teologias, filosofias, antropologias de muitas culturas, expressas em histórias ("mitos"), em textos sagrados, em sistemas filosóficos, em obras literárias, em criações artísticas, em rituais ou atos de culto, que envolvem (pelo menos este é o limite que colocamos para nossa pesquisa) a bacia do Mediterrâneo, e as diferentes culturas que se encontraram e se defrontaram nesta parte do mundo, entre Europa e Ásia, por alguns milênios.

\footnotetext{
5 LLOYD (1966).

$6 \quad$ Na Iliada 23, 880, uma pomba ferida por uma frechada de Merione morre exalando a sua força vital, chamada thymòs, o qual "voa" longe do corpo da pobre ave.
} 
As grandes concepções filosóficas e religiosas, às quais por vezes chegou esta contínua atividade morfogenética, são atraentes não só por sua grande beleza e capacidade de produzir maravilha, como disse Borges $^{7}$, nem pelas diferentes religiões ou crenças (ou fanatismos) que elas têm produzido nos séculos, com resultados por vezes sublimes e muitas vezes catastróficos:

elas parecem ainda ser um objeto privilegiado e um tubo de ensaio para estudar e compreender melhor o funcionamento dos sistemas de signos que aí entram em jogo, e o das formas e das estruturas em que são expressas, e por que não, para avaliar plenamente os efeitos pragmáticos e passionais que elas são capazes de produzir, até estabelecer as formas de comunicação e persuasão que circulam entre dominantes e dominados, entre emissores e destinatários dessa comunicação.

Em outras palavras, estas vastas concepções do mito e do discurso religioso podem, talvez, permitir-nos compreender melhor o funcionamento simbólico e metafórico da autoridade, e suas formas de controle da informação, da comunicação, com efeitos de persuasão e indução de aspectos "ficcionais" da "verdade", a fim de controlar as crenças, em uma pòlis, uma sociedade, ou em uma comunidade civil em geral.

Sem um controle dos mitos e das crenças não é possível construir e garantir uma forma de tradição, seja feita para durar milênios, seja improvisada por alguns anos ou décadas. E é necessário, para dizer bons mitos, fazer um bom uso das simetrias, atingir (alcançar) as estruturas profundas do conto, as sequências narrativas mais apropriadas: as provas (épreuves) extraordinárias que superar, competências no conhecimento da manipulação profética, ficções de combates cósmicos (aspecto "polêmico" do conto, da narratividade) que servem para definir a qualidade do herói, do rei, do deus, do "homem da Pronòia", da "Providência" e para estabelecer onde coloca-se o Bem e o Mal; e tudo isto, em um contexto narrativo amplo e profundo, suscetível (capaz) de fundar como tradição os fundamentos dos sistemas axiológicos (do sistema dos valores) dominantes em que as culturas são construídas.

Uma das "Sete Maravilhas" do mundo antigo, como é conhecida, foi uma estátua de Zeus sentado, esculpida em marfim e ouro, lindamente pintada, com altura de cerca de dez ou doze metros. Olhá-la, em sua o filosóficas por su valor estético y aun por lo que encierran de singular y de maravilloso". 
imponente beleza, dava uma sensação de bem estar, de esquecimento dos problemas e das angústias. Um Grego religioso ficava obrigado a vê-la pelo menos uma vez na vida.

No Partenon, uma estátua de Atena, também com uma dezena de metros de altura e também esculpida em marfim e ouro, era encimada por um capacete de ouro, cujos reflexos podiam ser vistos já a partir do mar, aproximando-se ao porto de Atenas ${ }^{8}$.

$\mathrm{Na}$ imaginação dos gregos, na idade arcaica e clássica - é trivial lembrá-lo - os deuses eram antropomórficos, isto é, eram uma mera projeção do mundo dos homens. Corpos masculinos e femininos, geração sexual (com algumas exceções prodigiosas, como o nascimento de Atena, a gestação de Dioniso na coxa do pai, e algumas partenogêneses primordiais), estrutura familiar e social hierárquica, sucessão genética de três ou quatro gerações, a origem da cosmos a partir do Vazio, isto é, do caos original, até o tempo "atual" (da atualidade), até chegar ao mundo ordenado (kòsmos) sob o governo de Zeus.

Um problema a mais é a relação (a mistura) sexual dos deuses com seres humanos, ainda que "heroicos" (heroínas ${ }^{9}$ ). Não podendo aparecer na essência total deles, que não teria sido tolerada fisicamente pelos seres humanos (como o mostra a história de Sêmele queimada e do duplo nascimento de Dioniso), para comunicar com os homens e as mulheres, os deuses tinham que operar alguma metamorfose, tomando o aspecto de um ser humano, ou mesmo de animais, pássaros, touros, etc., como é feito (se encontra) regularmente desde os tempos mais arcaicos que podemos reconstruir ${ }^{10}$.

O crescimento deles podia ser prodigiosamente acelerado no tempo (como Zeus ou Hermes, que crescem muito rapidamente após o nascimento), e seu tamanho, como também sugerido pelas estátuas gigantescas mencionadas, era bastante superior ao dos humanos.

Bastante complicado é também o problema da linguagem dos deuses: nos poemas homéricos acham-se interessantes vestígios de um duplo sistema lexical, uma "linguagem dos deuses" diferente da dos homens ${ }^{11}$.

8 É possível encontrar facilmente na Internet tentativas de reproduzir essa estátua colossal; para o capacete de Atena, cf. PAusan (I 28, 2).

9 Embora nunca sejam chamadas assim, mas só "mulheres", gynàikes.)

10 Sobre as metáforas em geral, cf. Forbes-Irving (1990) e Frontisi-Ducroux (2003).

11 Sobre os diversos registros da linguagem divina, cf. Ileana CHiRAss CoLombo, "I linguaggi speciali degli dei e la lingua di dio", in Morresi (1998, p. 83-103). Existem, porém, deusas de sexo feminino, terríveis e sedutoras, às quais se confere o epíteto de audèessa (Hом. V 334, Circe, 3 vezes, e Calipso uma só, XII, a quem se chama ainda de "ninfa", Ном. Od. V 14, 30; no verso V 159 ela é "dia theàon"; por outro lado, a filha de Cadmo, Ino Leukothea, antes de obter honras divinas era brotòs audèessa, V 334, ou seja, humana, mortal; cfr. HAINsworth 1989 ad l., que cita J. CLAY, "Demas 
Um texto bastante arcaico (fim VII - começo VI) nos fala de Deméter (Demèter) que mostra-se em forma de velha na casa de Celeo e Metanira. No momento de sua entrada, ainda deste modo, no aspecto de uma mulher velha e doente, a deusa roça com sua cabeça a abóbada do quarto (vv. 188-89, mèlatron), uma clara luz (sèlas) divina espalha-se no palácio real, causando aidòs, sèbas e medo "verde", dèos, nas meninas e na rainha. Nos versos 275 ss., a deusa manifesta-se, antes de partir, mudando estatura e aspecto, emanando do vestido dela um cheiro particular (veja-se a crença cristã no "cheiro de santidade"), e novamente emitindo luz, phèngos, para o corpo imortal que enche o palácio real de esplendor (aughè), semelhante a um raio, deixando a rainha sem palavras e estonteada por muito tempo (v. 271).

Mesmo a dieta (os alimentos) dos deuses era diferente da humana: gastavam o tempo em banquetes e simpósios, servidos por um escanção (por meninos, meninas, ou robôs metálicos feitos por Hefésto); seu alimento é a ambrôsia, seu vinho é o néktar, e em suas veias flui um líquido que não é chamado de sangue (hâima), mas de ikor.

Podem causar a morte de várias maneiras, com dardos invisíveis (metáfora de uma praga), com raios, ou de outras formas, e interferir com o mundo dos humanos através de sonhos, profecias e outras sèmata, como o trovão, o voo das aves etc. [Talvez, eles possam mesmo morrer].

Deslocam-se milagrosamente, como o voo de uma ave ou o caminho do arco-íris, viajando sobre o mar, em uma carruagem de ouro, e podem aparecer em sonhos, ou manifestar-se em forma humana (sósias) ou animal, transformando-se em vários aspectos. Seus poderes são consideráveis: eles têm a capacidade de desencadear tempestades, de lançar raios e trovões, de operar metamorfoses, sobre si mesmos ou sobre outros etc.

Na perspectiva de uma "descrição densa" (Clifford Geerz) das representações icônicas que podemos observar, a partir da idade arcaica até a época romana (devemos levar em consideração o fato de que trata-se de uma religião politeísta muito complexa, que desenvolveu-se ao longo de dois milênios), observei que um princípio geral da morfogênese do divino é a adaptação das formas empíricas de algums indivíduos animados (homens,

and Aude", «Hermes» 102 (1974, p. 129-36); cf. omphè.), que poderia significar "aquela que fala com voz humana", mas talvez ainda "aquela que fala a língua dos homens", usada aliás pelos deuses maiores quando assumem forma humana para se comunicar, com tal proteção, com algum dos mortais, seja em sonho, seja em vigília. Outro caso de entidades divinas "menores", mais próximas aos homens, é fornecido pelas divindades fluviais, que costumam se unir com ninfas ou com mulheres mortais; Posídon, por exemplo, transforma-se num deus fluvial, Enipeu, para seduzir Tiro (sobre a posição intermediária das Ninfas em relação a deuses e homens, cf. Hesiod., Fr. 304 Merk.-West). 
animais, mais raramente plantas) para configurar aspectos naturais, sejam eles figuras cósmicas (ou do ambiente circunstante), como a terra, o céu , as estrelas, as montanhas, o mar, os rios e as fontes, sejam ao contrário fenômenos atmosféricos, como os trovões, os raios (relâmpagos), os tufões ou furacões.

Neste tipo de representações são operantes as distorções mais habituais nas criações do imaginário, como as do tamanho (gigantismo, nanismo) ou, mais geralmente, as morfológicas, por exemplo: um número anormal de braços, cabeças, olhos, e muitas outras deformidades possíveis. Observa-se então, neste universo ficcional, o uso sistemático da associação de características morfológicas diferentes (não conformes com as percepções comuns, empíricas), para produzir várias hibridações, especialmente entre a figura humana e a de diferentes animais, isso é, para gerar uma série de figuras monstruosas, em geral violentas e predatórias.

Os estágios mais "arcaicos" destes processos semióticos do imaginário buscam representar os grandes eventos cosmológicos, tais como o nascimento (theo-gonia) de uma raça divina primordial (chamada "titânica"), por uma união entre o deus do céu, Urano, e a deusa da Terra, Gaia, desta maneira projetando por analogia sobre as figuras do cosmos alguns ícones de tipo humano, como as relações sexuais entre macho e fêmea, das quais deixo a vocês imaginar o tamanho ${ }^{12}$.

Dimensões igualmente "cósmicas" tomam as lutas (pòlemoi) pela soberania dinástica sobre o universo, que encontram-se em diferentes formas nas religiões do Oriente Próximo. Os gregos produziram histórias sagradas nas quais é-evidente a representação antropomórfica de catástrofes naturais, onde furacões, terremotos, deslizamentos de montanhas inteiras, erupções vulcânicas reconhecem-se na forma de uma luta (màkhê) entre sujeitos animados, embora sejam ultragigantescos, híbridos ou monstruosos.

Como um importante exemplo, podemos citar a Tifeomachia $^{13}$, ou seja, a luta de Zeus, que teve de enfrentar (depois de ter derrotado a geração anterior dos Titãs em um terrível conflito dinástico), um novo tipo de Antagonista, híbrido, gigantesco, monstruoso, chamado Typhon (Typháon).

Para além de qualquer consideração histórica e religiosa, e mantendo-se no nível (plano) da figuração ("figuratividade", seja narativa,

12 A religião egípcia, de uma maneira bastante significativa, imaginou um semelhante acoplamento, uma união (um coito) de um ser masculino com um feminino, isso é, entre Geb e Nut, mas inverteu o sexo dos dois elementos: o céu é do sexo feminino, a terra é do sexo masculino.

13 Cf. o verbete Theogonie etc. em Bonnefor (1981). 
seja icónica), é preciso notar que as fontes mais antigas descrevem uma imagem de Typhon que não corresponde a nenhuma das imagens reproduzidas na iconografia. É como se as possibilidades expressivas dos pintores ou escultores estivessem limitadas por restrições de ordem técnica, espacial (o que talvez é compreensível: se você pode, em um espaço pictórico vascular, reproduzir as três cabeças de Cérbero ou as nove da Hidra de Lerna, é muito menos fácil desenhar sobre um único corpo um conjunto redundante de cem braços ou cem cabeças de cobra). Isso acaba reduzindo significativamente as possibilidades reprodutivas (figurativas) do sinal icônico em comparação com as do conto, da narratividade, que parecem ser quase ilimitadas; os artistas da imagem, por vezes, parecem praticar (usar) uma espécie de "bricolage", na tentativa de representar o irrepresentável, a exemplo, a diacronia (Frontisi).

Hesíodo fala de Tiphàon (ou Typhôn), filho de Gaia e Tártaro, como de um monstro equipado com mãos e pés incansáveis, mas não indica o número, embora existam outros similares monstros enormes, que trazem suas deformidades em seu próprio nome, como os "Centimani" ou Hecatônquiros, "que têm cem mãos". Em seguida, ele acrescenta que "surgiam sobre seus ombros cem cabeças de serpente, dragão terrivel / que vibrava cem línguas pretas"; sob os cílios dos duzentos - assim parece que se deve deduzir - olhos serpentinos brilhava uma chama de fogo, e de todas estas cabeças coleava uma chama, quando esta criatura de pesadelo olhava para alguém. Além disso, as cem línguas proferiam uma ampla gama de sons, que vão desde uma linguagem compreensível para os deuses, até a emissão de mugidos de um boi ou de rugidos de um leão ${ }^{14}$.

As modalidades da luta estão ainda impregnadas das imagens mais antigas de um choque de forças naturais, como furacões, relâmpagos e trovões; alguns fenômenos descritos nos versos de Hesíodo (como a fusão das rochas) parecem mesmo aludir a erupções vulcânicas.

Quase 800 anos depois de Hesíodo, um mitógrafo chamado Apolodoro, autor da Bibliotheca, que organiza o que chamamos de "mitologia" grega, fornece uma versão da Typhon-(Tifono-)-machia, que expande o tamanho cósmico dos dois contendores. A representação "icônica" (a imagem verbal) do monstro varia significativamente, em comparação com a descrição de Hesíodo. Não há mais pés e mãos incansáveis, mas "uma natureza híbrida, de homem e de animal" ... sua forma até as coxas era a de um homem, mas tamanha era sua altura que superava todas as montanhas; das coxas 
para baixo ramificavam-se espirais de cobra (spèiras echidnòn); cem cabeças de serpente saltavam de seus braços, e a cabeça (humana?) tocava as estrelas. Se ele estendesse os braços, com um teria tocado o Ocidente, com outro o Oriente.

Macrobio, Saturn. I 20, 17, relata um oráculo ao Rei de Chipre Nicocreonte (época de Alexandre), no qual o deus Serapis (Sàrapis) ele mesmo descreve-se desta forma:

Eu sou um Deus feito assim, (você) aprender! qual eu digo: celeste cosmos é minha cabeça, a barriga é o mar a terra são os meus pés, minhas orelhas estão no éter meus olhos que brilham de longe, é a luz do sol brilhando!

E o sol era chamado "Olho de Zeus" já em Hesíodo ${ }^{15}$.

O trecho hesiódico de Tufão com cem cabeças localizadas sobre os ombros, é ligeiramente modificado: aqui elas estão dispostas ao longo dos braços, já não sobre seus ombros. Mas enquanto Hesíodo apenas descreve muitas cabeças de cobra, em Apolodoro Tufão tem embaixo das coxas enormes espirais de cobra, de acordo com um esquema figurativo que parece pertencer a outro tipo, ou seja, ao dos Gigantes ${ }^{16}$, com uma mescla bastante comum entre homem e serpente ${ }^{17}$.

A figura de Tufão (Typhon) aqui não apresenta cabeças de cobra em seus ombros (ou ao longo dos braços), mas tem uma forma serpentina na parte inferior do corpo (de acordo com a morfologia dos Gigantes). Além disso, deve-se notar, também tem duas grandes asas, sobre as quais parecem estar representados os muitos olhos do monstro, que também deviam ser desenhados em algum lugar.

Com base em Apolodoro (e, ao que parece, não em Hesíodo), Atanásio Kircher, muitos séculos depois, vai produzir esta imagem, juntamente com várias interpretações alegóricas, físicas e éticas ${ }^{18}$ :

Mais de dois mil anos separam Hesíodo e Kircher, e o "imaginário" (a atividade mental que produz imagems) continua utilizando este paradig-

15 Apollodoro, Bibl. I 6, 3. Macrobio, Saturn. I 20, 17. Cfr. Pettazzoni (1955, p. 100-103). Sobre a sobrevivência das figuras de Serapis, cf. SEZnec (1940, cit., p. 110 e nt. 6).

16 FABRE-SERris (1995, p. 55-56).

17 Confira, entre tantas, a figura reproduzida numa hídria de Cálcida, München Antikenslg., ca. 530 A.C. Sobre essas tipologias iconográficas do gigantismo, cf. a ampla pesquisa de VIAN (1952).

III volumes in folio.

8 A imagem está em: Athanasius Kircher, Oedipus Aegyptiacus, Romae 1652-1651, 


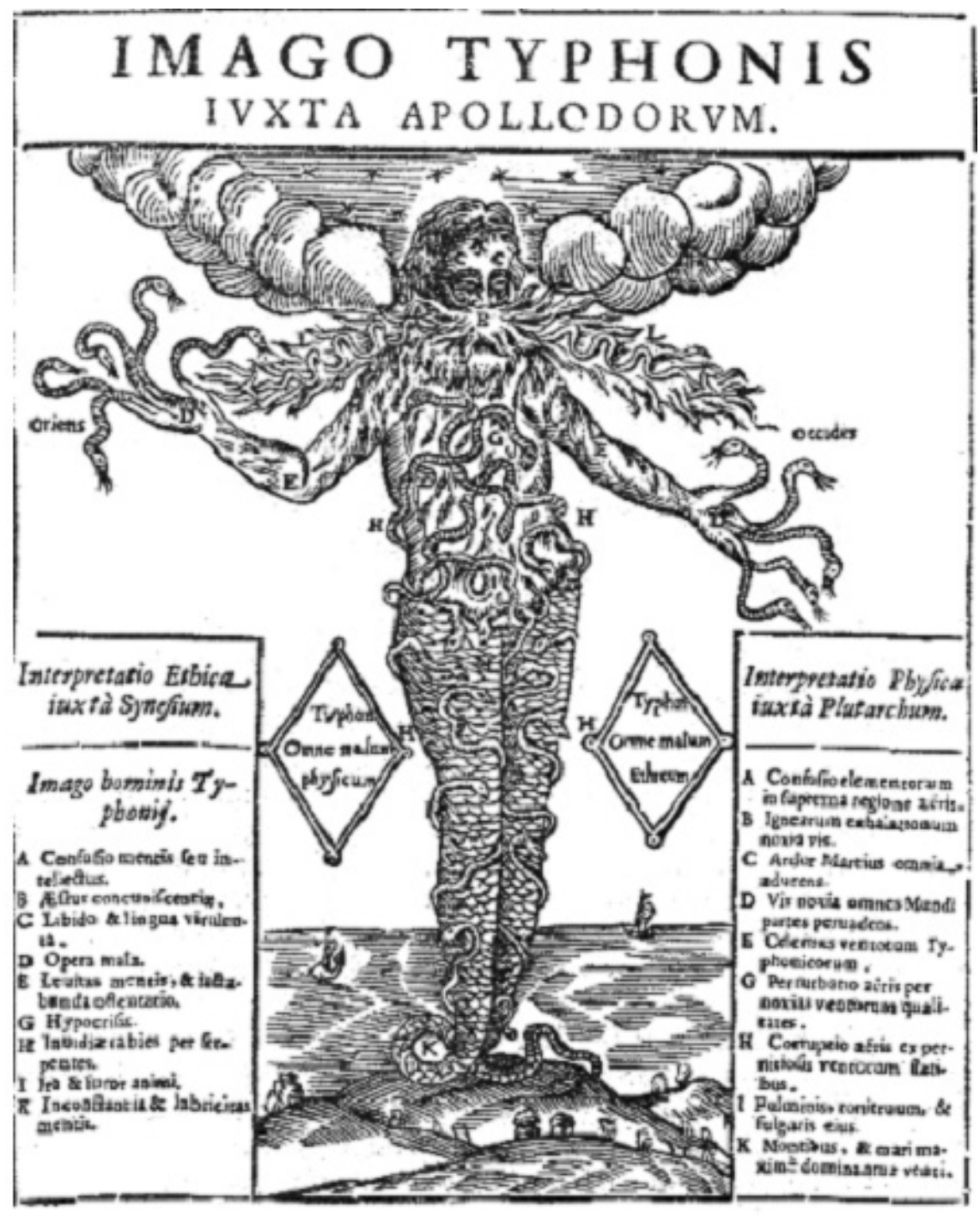

ma, estas estruturas de significação eficazes e significativas. Dimensões cósmicas, gigantismo, hibridismo, monstruosidade...

Assim, ao longo dos séculos, as antigas lutas para a soberania do cosmos tinham sofrido várias mesclas e sincretismos, todavia mantendo algumas estruturas espaciais, temporais e dinâmicas.

O que permaneceu (como vê-se, por exemplo, na primeira parte das Metamorfoses de Ovídio) foram imagens como: 
a. a separação dos elementos cósmicos (Staudacher) ${ }^{19}$;

b. a função geradora da Terra,

c. uma sucessão de gerações divinas,

d. uma sucessão de idades da raça humana, em gradual declínio e deterioração.

E ainda:

e. uma série de lutas, de provas que o deus dominante (Zeus) deve enfrentar para formar um cosmos ordenado, de combates contra monstruosas forças primordiais,

e, finalmente,

f. uma ou mais imagens da origem dos homens, isso é, uma antropogonia.

Estas estruturas profundas levam a uma multidão de figuras, por vezes grandiosas, do imaginário, mas ainda podem levar a uma confusão, a diversas formas sincréticas, que também podem coexistir uma a lado da outra ${ }^{20}$, em uma espécie de bricolage da lógica do pensamento "mitopoético".

Os homens, por exemplo, podem surgir de um carvalho (quercus) ou uma rocha, das pedras de Deucalião e Pyrra ou do sangue dos Gigantes fertilizado pela Terra (Gaia); podem ter nascido a partir das cinzas do Filho de Zeus (Dionisos) e dos Titãs, queimados por um raio arremessado pelo Pai dos deuses e dos homens. Ou podem ter a origem de um ovo cósmico, ou de uma mistura de lama e água, animada por um sopro divino (Pnèuma), ou mesmo a partir do esperma de um deus coxo, derramado nos sulcos da Terra Mãe.

o nascimento de alguns heróis fundadores ("autóctonos") da Terra mesma (Gàia), mostra algumas interessantes invenções icônicas, na tentativa de representar a autoctonia ${ }^{21}$, com o expediente de imaginar um corpo feminino "materno" que emerge do chão até a metade do tronco, e entrega o bebê nas mãos das mulheres que terão de criá-1 $\mathrm{o}^{22}$.

Uma religião mais do que milenar, que nunca em sua longa história produziu livros ou dogmas, deu um espaço considerável à criação literária e figurativa. Isso parece explicar, pelo menos em parte, o caráter "poético", que pelo menos desde o tempo de Chr. Gottlob Heine é atribuído à religião

19 Feita em Ovídio por um misterioso demiurgo, um deus "desconhecido" (àgnostos theòs): I 73: Quisquis fuit ille deorum.

20 Não é preciso lembrar que a civilização grega não conhece uma ortodoxia religiosa, com uma única cosmogonia, teogonia e antropogonia, mas produz muitas e diversas variações.

21 Sobre a questão da autoctonia na Grécia, cf. Loraux (1996).

22 Cf. por exemplo as imagens de um certo Stamnos de Vulci, ca. 460 a.C. Gaia ou Gêa emerge do solo tendo no braço o pequeno Erecthèus e estendendo a mão a Atena, sob o olhar satisfeito de Efesto (LIMC, Ge 16, p. 173). 
grega, ou - se você quiser - as qualidades estéticas únicas (peculiares) da "mitologia" grega, acúmulo ou agregação de materiais narrativos que (no caso em que não seja reconhecido como o discurso religioso de um politeísmo complexo), leva o nome, genérico, mas significativo, de História poetica, para citar o título de uma famosa obra "mitográfica" de Thomas Gale (Parisiis, 1675).

Na nossa análise das morfologias do imaginário no mundo Mediterrâneo antigo, então, continua a surpreender-nos a quantidade e a beleza das grandes concepções filosóficas e religiosas produzidas pela cultura grega, e é uma surpresa (thàuma) principalmente (sobretudo) de ordem estética.

[Todavia hoje, apesar disso, existe no mundo uma religião, dita Dodecateismo, que pratica rituais e venera os deuses do Olimpo, com muitos adeptos (max 500.000 - min. 5.000).]

Por um lado, uma vasta sinédoque universal explica tudo o que existe, com base em algumas analogias antropomórficas e zoomórficas, e descreve a geração dos deuses, com base em uniões sexuais semelhantes as dos seres humanos: o Céu, Urano, aproxima-se da Terra (Gàia) "dominado por um forte desejo", e as relações entre os deuses reproduzem a estrutura social do mundo humano.

Do lado oposto, acham no espaço as abstrações mais ousadas, assim que o Cosmos, o Ser (tò on), e especialmente o Deus que os criou (que criou todo isso, em suma, todo o que existe), são retratados como substâncias imateriais; enquanto os objetos (os seres) "gerados" do mundo material, podem ser preenchidos por um sopro, uma respiração imaterial que os anima, e podem ser variadamente mesclados a partir duma dinâmica de atração e repulsão, pelo ódio, pela discórdia (Nèikos, Pòlemos) ou pelo amor, pela Philía ou Philotes, pelo Himeros, e finalmente pelo Eros. Se nas concepções "aéreas" do divino (Pnèuma, Spiritus, Anima Mundi), pode-se ainda reconhecer um traço residual de "fisicidade" 23 , um passo ulterior na direção da abstração (como a ideia magnífica de uma enorme bola, uma esfera global), ou seja, na direção de um discurso totalmente não-figurativo, levará a conceber o divino como uma Palavra criadora (Lògos), que tende a formas puramente intelectuais: Phrèn, Noùs, ou Lògos, isso é, a Palavra (Verbum), que pressupõe uma pura Mente, um Intelecto divino que anima, 
que infunde alma ao Universo ${ }^{24}$. O potencial morfogenético desta oposição, deste esquema opositivo (visivel // invisivel, material // imaterial, materia // espírito), como você pode imaginar, é enorme.

Se os aspectos filosóficos e religiosos deste problema vão muito além das limitações dessas poucas reflexões, vamos apenas concluir recordando algumas das vastas consequências desta fundamental oposição figurativo // não-figurativo (ou abstrato).

No final de uma civilização que chegou, provavelmente, ao ponto mais elevado da iconicidade e da representação antropomórfica do divino, uma nova religião, que se referia a concepções abstratas de diferente origem (neoplatônica, estoica, judaica, etc.), tentará, a partir da polêmica contra os deuses do politeismo grego e romano, (èidola, os falsos ídolos do "paganismo"), a via da recusa do iconismo, a renúncia à figuração, que pode ser resumida com uma frase retirada de Paulo de Tarso, citada por Clemente de Alexandria:

"Para nós, os ídolos não são nada, no cosmos" (Epist. aos Coríntios. I 8, 4), uma vez que não é possível (lícito) para nós que exista qualquer representação de Deus nas coisas criadas (Strom. VI $18,163.1)^{25}$.

Mas cerca de oito séculos atrás já havia se levantado a animada bem como ignorada pela gente comum - controvérsia (crítica) dos primeiros "filósofos" contra todas as formas de representação icônica ou antropomórfica do divino, por exemplo, de Xenófanes ou de Empédocles: basta aqui lembrar Heráclito (o mestre de Éfeso chamado o "obscuro", skoteinòs), para a eficácia do seu desdenhoso sarcasmo contra aqueles que adoram as estátuas:

\footnotetext{
"e oram às estátuas (agàlmata), como se alguém falasse com as paredes da sua casa (domòisi)!” (Fr. 5 D.-K.) ${ }^{26}$.
}

24 Por volta do século VI a.C., os primeiros sábios da Jônia, aqueles que chamamos de filósofos, começaram a criticar com feroz ironia a concepção de figuras antropomórficas dos deuses, negando tanto que um deus possa morrer quanto que possa nascer, ser gerado por alguém. Esses filósofos propuseram concepções mais abstratas do Ser (tò òn, p. ex. em Parmênide), representando-o como uma perfeita Esfera, e refutaram com firmeza a ideia que se possa atribuir aos deuses membros e formas semelhantes às do homem; cf. JAEGER (1953), em particular o Cap. III, dedicado a Xenófanes de Colofonte.

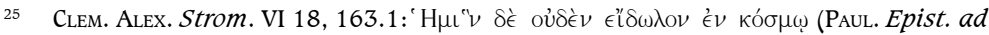

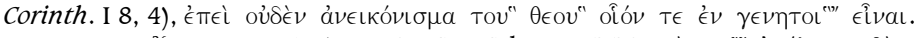

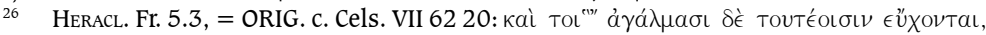

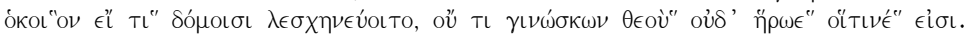


A arte bizantina - com base no legado do mundo grego e romanoescolheu quanto ao resto o caminho oposto, representando de bom grado o Cristo Pantokràtor ou a Virgem Theotòkos (a Madre de deus) em inumeráveis "ícones", mosaicos, etc.; mas outras religiões preferiram seguir o caminho da irrepresentabilidade do divino, ou pior, da condenação geral e destruição das imagens religiosas ${ }^{27}$. A história de Bizâncio conhecerá polêmicas ferozes, que não serão somente filosóficas ou teológicas, entre os iconoclastas e os iconodúlios (ou idólatras, eijdwlolavtrai, ainda Paulo de Tarso, juntando-os com os ladrões, com os prostitutos, os adúlteros e os sodomitas ${ }^{28}$ ).

E certamente, ainda hoje há grandes religiões monoteístas que não permitem a prática semiótica de representar o divino em imagens semelhantes as dos seres humanos, embora seja dito muito claramente, em um livro sagrado essencial, que Deus criou o homem (e a mulher?) "à sua imagem e semelhança".

No grego dos Setenta:

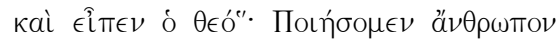

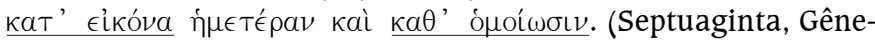
sis, 1,27).

Se no Antigo Testamento permanecem apenas alguns (embora eloquentes) vestígios do antropomorfismo do Deus de Abraão, se não é permitido no Islã representar Deus em forma humana, mesmo no cristianismo oriental apareceu (insinuou-se) uma tendência a considerar a adoração de imagens como blasfema.

A herança do mundo greco-romano, por outro lado, ofereceu uma das religiões mais produtivas de imagems e de histórias de deuses antropomórficos, até demasiado humanos ${ }^{29}$, que as civilizações com escritura já conheceram (não sei a situação do hinduísmo, que parece ser muito "iconodulo").

Se não tivessem triunfado, na cultura (religiosa) europeia, - e não sem vastos derramamentos de sangue - os iconodúlios (que é dizer, nós mesmos) - nunca teriam nascido inúmeras obras de arte, desde os mosaicos bizantinos de Ravena, à Pietà de Michelangelo, desde Giotto à arte sacra de muitos séculos, que continua criando e gerando beleza até hoje - e esperemos que continue por muito tempo mais.

disto.

27 A destruição idiota dos Buddhas de Bamyan, no Afganistão, é uma boa demonstração

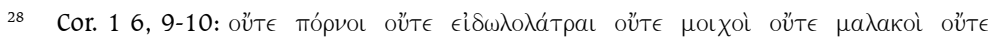

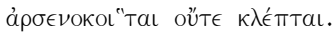

29 Menschliches, Allzumenschliches, Nietzsche, 1878. 
Assim, por exemplo, o grande afresco da Criação, um tema amplamente desenvolvido no filme de Hollywood "Agonia e Êxtase" (ano 1965, de Carol Reed, com Charlton Heston), na Capela Sistina, no Vaticano, poderia hoje ser considerado blasfêmia.

\title{
RESUMO
}

Analisam-se alguns mecanismos para descrever as estruturas básicas do universo, e algumas figuras divinas - as imagens de deuses masculinos e femininos - em termos de analogia com as formas do corpo humano. Gigantismo, dimensões cósmicas, distorções morfológicas, macrocosmo e microcosmo. Confrontam-se algumas diferentes concepções de cosmoteísmo (deus sive natura), com a proibição de produzir imagens de divindades. As civilizações do Mediterrâneo antigo encontraram diferentes respostas e soluções para o problema de dar forma à ideia da divindade, com representaões muito diversificadas.

Palavras-chave: concepções de gigantismo; imagens míticas do feminino e do masculino; gênero e religião.

\begin{abstract}
This paper examines some mechanisms to describe the basic structures of the universe, and some divine figures - the image of male and female gods - in terms of analogy with the human body shapes. Gigantism, cosmic dimensions, morphological distortion, macrocosm and microcosm. Though the ancient Mediterranean civilizations found different answers and solutions to the problem of forming the idea of divinity, with very diverse representations, face some different conceptions of the cosmos, theism (deus sive natura), as the prohibition of producing images deities.
\end{abstract}

Keywords: conceptions of gigantism; mythic images of femininity and masculinity; gender and religion.

\section{REFERÊNCIAS}

ASSMANN, J. Das kulturelle Gedächtnis: Schrift, Erinnerung und politische Identität in frühen Hochkulturen. München: Beck, 1992 (trad. it. Einaudi. Torino, 1997).

. Moses der Ägypter: Entzifferung einer Gedächtinsspur. München - Wien: Hanser, 1998

(trad. it. Adephi. Milano, 2000). 
BONNEFOY, Y. (Cur.). Dictionnaire des Mythologies. Paris: Flammarion, 1981.

BURKERT, W. C. Princeton: Harvard University Press, 1996. (trad. it. Adelphi. Milano, 2004).

BORGES, Jorge Luis. Otras inquisiciones. Buenos Aires: Editorial Sur, 1952.

CALAME, C. Masques d'autorité: Fiction et pragmatique dans la poétique grecque antique. (L'âne d'or). Paris: Les Belles Lettres, 2005.

CLAY, J. Demas and Aude: The Nature of Divine Transformation in Homer. Hermes, v. 102, p. 129-36, 1974

FABRE-SERRIS, J. Mythe et poésie dans les Metamorphoses d'Ovide. Paris: Klincksieck, 1995.

FORBES-IRVING, P. M. C. Metamorphosis in Greek Myths. Oxford: Clarendon Press, 1990.

FRONTISI-DUCROUX, F. L'homme-cerf et la femme-araignée: Figures grecques de la métamorphose. Paris: Gallimard, 2003.

GALES, Thomas. Historiae poeticae scriptores antiqui: Apollodorus Atheniensis, Conon Grammaticus, Ptolemaeus Hephaest. F., Parthenius Nicaensis, Antoninus Liberalis: Graecè \& Latiné: accessêre breves notae $\mathcal{Q}$ indices necessarij. Parisiis: Typis F. Muguet; Prostant apud R. Scott, bibliopolam Londinensem, MDCLXX [1675].

HAINSWORTH, J. B. Omero. Odissea, v. 2. Milano: Mondadori, 1982 (Coll. Lorenzo Valla).

JAEGER, W. Die Theologie der frühen griechischen Denker. Stuttgart: Kohlhammer, 1953 (trad. it. Nuova Italia: Firenze, 1961).

LIMC: Lexicon Iconographicum Mythologiae Classicae, I-VIII tt. (+ Indici). Zürich-München: Artemis Verlag, 1981-1999.

LINCOLN, B. Authority: Construction and Corrosion. Chicago: Univ. Press, 1994 (tr. it. Einaudi. Torino 2000, con Introduzione di Maurizio Bettini).

LLOYD, G. E. R. Polarity and Analogy: Two Types of Argumentation in Early Greek Thought. Cambridge: Cambridge University Press, 1966

LORAUX, N. Né de la Terre. Paris: Seuil, 1996 (trad. it. Meltemi. Roma, 1998).

MORRESI, R. Le lingue speciali. Atti del convegno di studi, Università di Macerata 17-19 ottobre 1994. Roma: Il Calamo, 1998.

NIETZSCHE, F. Menschliches, Allzumenschliches. Chemnitz: E. Schmeitzner, 2 v., 1878.

PETTAZZONI, R. L'onniscienza di dio. Torino: Einaudi, 1955.

REITZENSTEIN, R.; SCHAEDER, H. H. Studien zum antiken synkretismus aus Iran und Griechenland. Leipzig und Berlin: Wissenschaftliche Buchgesellschaft, 1926.

SAXL, Fritz. Macrocosm and Microcosm in Mediaeval Pictures. Saxl Lectures,v. 1. London: The Warburg Institute, University of London, 1957, p. 58-72.

SEZNEC, J. La survivance des dieux antiques. London: Warburg 1940, rist. Paris: Flammarion, 1980 (tr. ingl. The Survival of Pagan Gods; the Mythological Tradition and its Place in Renaissance, Humanism and Art. New York, 1953).

VIAN, F. La guerre des Géants: Le mythe avant l'époque hellénistique. Paris: Klincksieck, 1952.

Submetido em: 29/04/2010

Aceito em 26/07/2010 